\title{
Our parents' keepers? - Making more of ethics in old age psychiatry
}

Declan Lyons

Ir J Psych Med 2002; 19(3): 74-75

Ethics, derived from the Greek ethikos, meaning 'disposition' may at first glance seem to have more to do with philosophy than medical science. It refers to the study of conduct with respect to whether an action is right or wrong, and to the goodness and badness of motives and ends of a given action. Far from being the preserve of academic philosophers however, ethically demanding situations occur with remarkable frequency in the practice of old age psychiatry. As clinicians our actions and inactions must withstand scrutiny not just against a set of widely acknowledged standards or a code of conduct but often against the flimsiest of unenforcable guidelines.

Stereotypes about the elderly are often powerful in their ability to convey negative and fearful images of incompetence, dependence and decay in physical and mental abilities. Societal views of older people have thus the potential not only to deprive older patients of autonomy but to even lead to deeply ingrained discrimination in terms of access to health care resources. Facilitating the exercise of autonomy by sufferers of illnesses like dementia, in a health care system which views being old as being synonymous with being ill, is extremely challenging.

Dilemmas about treatment decisions exist however, not only because of prognostic considerations, but also because of the expense and scarcity of many high technology therapies. Logic alone tells us that invasive therapies are not in the interest of each and every older patient, yet as long as we treat 'the elderly' as a single homogeneous mass, the ethical aspects of decision making may be subverted in the face of purely rigid clinical considerations.

\section{Core principles}

Older mentally ill people may, by virtue of their distress and dysfunction due to illnesses like dementia, be among the most vulnerable of any group in society. In dealing with the multiplicity of practical problems that may arise, the well accepted ethical principles of autonomy, beneficence (providing) benefits and balancing them against risks), non-maleficence (avoiding the causation of harm) and justice (fairness in the distribution of benefits and risks) merit consideration especially in terms of clinical decision-making on behalf of those lacking mental capacity. ${ }^{1}$ These principles are only relevant to the extent that they seem to apply to a given set of circumstances and taking every nuance of every moral

Declan Lyons, Consultant Psychiatrist, Old Age Psychiatry, St Patrick's Hospital, Ireland.

SUBMTTED: MARCH 7, 2002. ACCEPTED: AUGUST 27, 2002 dilemma into account may be impossible. Gathering information can often help solve seemingly intractable problems or at least clarify which set of ethical principles may be most important to consider.

The situation is further complicated by the fact that what is ethical may not be strictly lawful - the two are related but not synonymous. A clinician may for example regard it as ethical to follow the exact terms of an advance directive (to withhold ECT for instance) irrespective of circumstances but statute law as it stands doesn't compel anyone to do this. Good ethical practice instead demands consideration of all factors in the context of an individual situation and such an advance directive may be only a part of this. Weighting the relative importance of each ethical principle at a given time is also critical to achieving balanced and accountable clinical decision-making.

\section{Brokering the power}

Respect for personal autonomy has been a rallying cry behind challenges to the often hitherto primacy of doctor's views on the process of medical decision making. Paternalism has come to take on ageist, threatening and pejorative connotations. There may be occasions however where justification may be made for deciding on behalf of patients in the case of an unconscious patient or the willing abrogation of the right to decide for oneself. Competency is a central issue though, and when reduced or absent can lead to the discounting by others of clearly spoken prior wishes and intentions. The process of judging capacity at all, even with the intention of preserving a person's power and independence, may be said to be still a modified form of paternalism ${ }^{2}$ as the power still very much resides with us - we decide who is capable of autonomous choice.

Post in his book 'The moral challenge of Alzheimer's disease' ${ }^{3}$ highlights the dangers of putting too much emphasis on rationality and memory in judging worth and personhood. Post refers to a 'hypercognitive culture' which excludes people with dementia from dignity and respect and lays the way open for devaluation, neglect and even abuse by society. As clinicians we run the risk of participating in healthcare systems that discriminate against older people, however unintentionally or subtly, unless we review and criticise our own value judgements about personhood and quality of life.

Our colleagues in primary care may also look on us to take the lead in promoting greater awareness of issues like elder abuse. This practice remains a largely invisible problem in the community, but one which a substantial proportion of our community dwelling patients remain at risk of. ${ }^{4}$ Practising medicine in an ethical vacuum can also serve to perpetuate 
mistreatment by proxy as older persons are often perceived as being at the fringes in terms of priority resource allocation in tertiary as well as community care settings. Equally where thoughtless, stereotyped and poorly informed societal perceptions of older people hold sway, our patients are liable to be unwanted, discarded and abused.

The failure to consider the impact of potentially invasive treatments like cardiopulmonary resuscitation (CPR) may conversely lead to inappropriate and undignified life sustaining measures being carried out on hospital patients whose chances of procuring benefit from them are slim. ${ }^{5}$

How often do we seek to limit such interventions by sensitively exploring the wishes of patients and families while ensuring other care is not restricted or denied? When the ethical principles of respect for autonomy and justice are ignored, however unwittingly, the consequences of over-treatment or under-treatment can be equally malignant and respect denying for the vulnerable older person.

\section{Clearing the haze}

Moving forward into a new millennium poses challenges for all health professionals in respect of operating ethically based health strategies at individual patient and planning levels. The capacity to benefit from treatment has to be considered whatever the age of the individual and measuring this benefit has to take not only medical and economic factors but also ethical issues into account.

Legal and ethical issues need to be at the core of every undergraduate and postgraduate curriculum to enhance understanding of their relevance. Continuing professional development also needs to impart information and skills to practitioners of all disciplines, particularly those interfacing with older persons, to allow competent, reasoned and transparent decision-making.

At an individual college faculty level, ethics needs to be given greater priority and the unambiguous message sent out that debate should be promoted as widely as possible with other bodies, both lay and professional, as no single institution or professional grouping has a monopoly on ethical wisdom. Communication skills training is also now thankfully becoming an important element in medical training to help counter the remote and aloof image that could be said to have characterised medical proxy decision-making in the past.

Sustaining such an approach or even not challenging the perception, in the face of evolving multidisciplinary decisionmaking in virtually every medical subspecialty, would be anachronistic in the extreme.

High psychological and physical demands are placed on families and caregivers of people with illnesses like dementia and practical intervention programmes to support carers at an earlier stage are needed to counter elder mistreatment and neglect. Broad based care and carer-training packages along with access to support services is probably the best way to ensure a high standard of care for the community dwelling mentally ill. We need to be more proactive in calling for such measures - it is insufficient to merely express sympathy for families' predicaments. It may be impossible to practise ethically sound medicine in a context of scarce resources.

The appropriate mechanism to address many ethical issues may vary from consulting one's conscience, obtaining guidance from codes of conduct, laws or agreed norms of practice yet the key objective must be to try and find balance given the exact situation and relevant circumstances.

If we seek flexibility in terms of avoiding excessively legalistic and bureaucratic controls over good professional practice, then the onus is on us to demonstrate concern for patient autonomy and simultaneously win trust by openly inviting input from families, advocates and other concerned parties. The best care is likely where most decisions are taken flexibly and properly at grass roots level. Asserting this message on behalf of our patients and demonstrating good ethical practice will help make this objective a reality.

\section{Declaration of Interest: None}

\section{References}

1. Block S, Chodoff P. Psychiatric Ethics, Oxford University Press: 1991; 58. 2. Bloch S, Chodoff P, Green SA. Psychiatric Ethics, Oxford University Press: 1999; 322.

3. Post S J. The moral challenge of Alzheimer's disease. London: Johns Hopkins University Press: 1995

4. McCreadie C, Bennett G, Gilthorpe M.S, Houghton G, Tinker A. Elder abuse: do general practitioners know or care? Journal of the Royal Society of Medicine 2000: 93 : 67-71.

5. Lyons D, Mulcahy R, O'Neill. D. How far should we go? The extent to which doctors choose to resuscitate patients. Journal of the Irish Colleges of Physicians and Surgeons 2002: 31;1: 28-31. 
